\title{
BMJ Open Prognostic and clinicopathological significance of pretreatment mean platelet volume in cancer: a meta- analysis
}

\author{
Xin Chen (D) , ${ }^{1,2}$ Jing Li, ${ }^{3,4}$ Xunlei Zhang, ${ }^{5,6}$ Yushan Liu, ${ }^{7}$ Jindong Wu, ${ }^{1}$ \\ Yangcheng $\mathrm{Li}^{1}{ }^{1}$ Xiaopeng Cui, ${ }^{8}$ Xiaohui Jiang ${ }^{1}$
}

To cite: Chen $X$, Li J, Zhang $X$, et al. Prognostic and clinicopathological significance of pretreatment mean platelet volume in cancer: a meta-analysis. BMJ Open 2020;10:e037614. doi:10.1136/ bmjopen-2020-037614

- Prepublication history and additional material for this paper are available online. To view these files, please visit the journal online (http://dx.doi. org/10.1136/bmjopen-2020037614).

$\mathrm{XC}, \mathrm{JL}$ and $\mathrm{XZ}$ contributed equally.

Received 21 February 2020 Revised 03 August 2020 Accepted 23 August 2020
Check for updates

(C) Author(s) (or their employer(s)) 2020. Re-use permitted under CC BY-NC. No commercial re-use. See rights and permissions. Published by BMJ.

For numbered affiliations see end of article.

\section{Correspondence to} Professor Xiaohui Jiang; jxhyjl@163.com and Professor Xiaopeng Cui; cxp@ntu.edu.cn

\section{ABSTRACT}

Objective Our study aimed to evaluate the prognostic and clinicopathological significance of pretreatment mean platelet volume (MPV) on cancer by using meta-analysis of published studies.

Design Meta-analysis.

Data sources Relevant studies available before 22 December 2019 were identified by searching MEDLINE, EMBASE.

Eligibility criteria All published studies that assessed the prognostic and clinicopathological significance of pretreatment MPV on cancer were included.

Data extraction and synthesis Studies were identified and extracted by two reviewers independently. The $\mathrm{HR} / \mathrm{OR}$ and its $95 \%$ Cls of survival outcomes and clinicopathological parameters were calculated.

Results A total of 38 eligible studies (41 subsets) with 9894 patients with cancer were included in the final metaanalysis. MPV level was not significantly associated with both overall survival ( $\mathrm{HR} 0.98,95 \% \mathrm{Cl} 0.84$ to 1.14 ) and disease-free survival (HR $1.22,95 \% \mathrm{Cl} 0.86$ to 1.73 ) of patients with cancer. Neither advanced nor mixed-stage tumour patients showed significant association between MPV and overall survival (HR 1.36, 95\% $\mathrm{Cl} 0.96$ to 1.94 , HR $0.90,95 \% \mathrm{Cl} 0.74$ to 1.09). However, high MPV had the strongest relationship with poor overall survival (HR 2.01; $95 \% \mathrm{Cl} 1.08$ to 3.41 ) in gastric cancer, followed by pancreatic cancer (HR 1.54; 95\% Cl 1.31 to 1.82). Whereas in the subgroup using receiver operating characteristic curve method to define cut-off values, low MPV was significantly related to poor overall survival (HR 0.78 , $95 \% \mathrm{Cl} 0.64$ to 0.95 ). In addition, MPV had no significant association with age (OR $0.96,95 \% \mathrm{Cl} 0.90$ to 1.02 ), sex (OR $1.04,95 \% \mathrm{Cl} 1.00$ to 1.09), depth of cancer invasion (OR $0.90,95 \% \mathrm{Cl} 0.77$ to 1.04 ) and tumour stage (OR 0.91, $95 \% \mathrm{Cl} 0.78$ to 1.07$)$.

Conclusions Pretreatment MPV level is of no clearly prognostic significance in cancers and no significant association with clinicopathological parameters of patients with cancers.

\section{INTRODUCTION}

Cancer is one of the main causes of morbidity and mortality worldwide. ${ }^{1}$ Despite the advance of new anticancer drug application
Strengths and limitations of this study

This is the first meta-analysis of exploring the association between pretreatment mean platelet volume and cancer prognosis.

- The current study provided a comprehensive assessment of association between mean platelet volume and cancer survival, and showed significant findings.

- Strong and reliable methodological and statistical procedures were applied.

- Almost all of the included studies were retrospective, and the patients included were all but composed of Asian, which may have led to greater susceptibility to bias.

and surgical techniques, the survival of most tumours is still not optimistic. ${ }^{2}$ Therefore, finding potent indicators to predict the prognosis of cancer patient is justified with the purpose to design an appropriate therapeutic scheme to improve the patient survival.

Mean platelet volume (MPV), the most commonly used measure of platelet size, is considered to be an effective hallmark of platelet activation. ${ }^{3}$ The complicated interactions between activated platelets and cancer cells lead to tumour growth, aberrant angiogenesis, invasion and metastasis. ${ }^{4-6} \mathrm{~A}$ mounting body of evidence suggests that MPV plays an important prognostic role in various types of tumours, including upper gastrointestinal tumours, ${ }^{7-14}$ colorectal cancer, ${ }^{15}{ }^{16}$ lung cancer, ${ }^{17-19}$ breast cancer ${ }^{20-22}$ and urothelial carcinoma. ${ }^{23}$ However, the association between MPV level and cancer prognosis has not been comprehensively investigated due to the inevitable heterogeneity of the samples in different studies.

Therefore, we performed this meta-analysis to investigate the possible association between MPV level and clinical outcomes of cancer 
patients and evaluate the significance of MPV as an effective biomarker of cancer prognosis.

\section{METHODS}

\section{Search strategy and election criteria}

Relevant studies were obtained from MEDLINE and EMBASE up to 22 December 2019. Language restrictions were not applied during the database search. Medical subject headings were searched and we performed a search of titles and abstracts combined with the following key words: ("mean platelet volume OR platelet volume, mean OR MPV") and ("neoplasms OR cancer OR tumor OR carcinoma"). The references of the included articles were also scanned to find additional relevant studies. A detailed search strategy was showed in online supplemental table 1 (using MEDLINE as an example). The search results were then reviewed according to the following inclusion and exclusion criteria: (1) studies should assess the value of MPV prior to any treatment in patients with proven pathological diagnosis of cancer, (2) studies should evaluate the relationship between MPV and prognostic value or clinicopathological features of cancer patients, (3) studies should provide HR with a 95\% CI for clinical outcomes, or abundant data to estimate these quantities, (4) non-English articles were excluded, (5) non-human studies or basic research papers, reviews, meta-analyses, case reports, letters and irrelevant topics were not eligible for our meta-analysis. Two reviewers independently performed the study selection and resolved any disagreements via discussion.

\section{Data extraction and quality evaluation}

In current meta-analysis, two researchers (XZ and YL) independently checked each included article and collected relative data, such as name of first author, publication year, country, study type, study period, follow-up time, sample size, cancer type, cancer stage, cut-off value of MPV, definition method of cut-offs, HR data (univariate or multivariate) and the number of patients with various clinicopathological features, such as tumour location, differentiation, size, depth of tumour invasion and TNM ( Tumor, Lymph Node, Metastasis ) stage. HRs and 95\% CIs were extracted for overall survival (OS), diseasefree survival (DFS), progression-free survival (PFS) and recurrence-free survival (RFS). The Newcastle-Ottawa Scale was used to evaluate the quality of each study with eight items on methodology from three dimensions: selection, comparability and exposure. ${ }^{25}$ Two investigators indepentently assessed all studies and scored them, among which scores of 6 or higher were qualified. All disagreements were settled by consensus.

\section{Outcomes}

We defined OS as the time from the study enrolment to the date of death from any cause or last follow-up. Since DFS, PFS and RFS share similar endpoints, they were analysed together as one outcome, DFS. ${ }^{26-28}$

\section{Statistical analyses}

All analyses were performed by using STATA V.14.0 (STATA). HR with 95\% CI was obtained directly from each included study if available or were calculated from the necessary data according to the methods published for the analysis of pooled outcomes. ${ }^{29}$ The heterogeneity in the analysis was assessed using Cochran's $Q$ test and Higgins I-squared statistic. A random-effects model (DerSimonian-Laird method) was applied when a $\mathrm{p}<0.1$ for the Q-test or $\mathrm{I}^{2}>50 \%,{ }^{30}$ suggesting the presence of significantly heterogeneity among the included studies. Otherwise, a fixed effects model (MantelHaenszel method) was conducted for pooled data. ${ }^{31}$ ORs and 95\% CIs were used to analyse the relationship between MPV and clinicopathological factors by using $\chi^{2}$ test. Subgroup analysis based on tumour type, tumour stage, age, country of origin, cut-off value and method of defining the cut-off value were conducted to determine whether there was potential heterogeneity among the eligible studies. Moreover, sensitivity analysis was performed by removing every single study sequentially at a time to evaluate whether individual study influenced the combined effect and validate the robustness and credibility of the pooled outcomes. Publication bias of literature was estimated by Begg's funnel plot ${ }^{32}$ and Egger's linear regression tests, ${ }^{33}$ and $p>0.05$ indicated no significant publication bias.

\section{RESULTS}

\section{Selection and characteristics of studies}

In the current study, identified 900 records were identified as potentially relevants through our literature search. two hundred and seventy-six duplicates were excluded. After screening titles and abstracts, 579 studies with

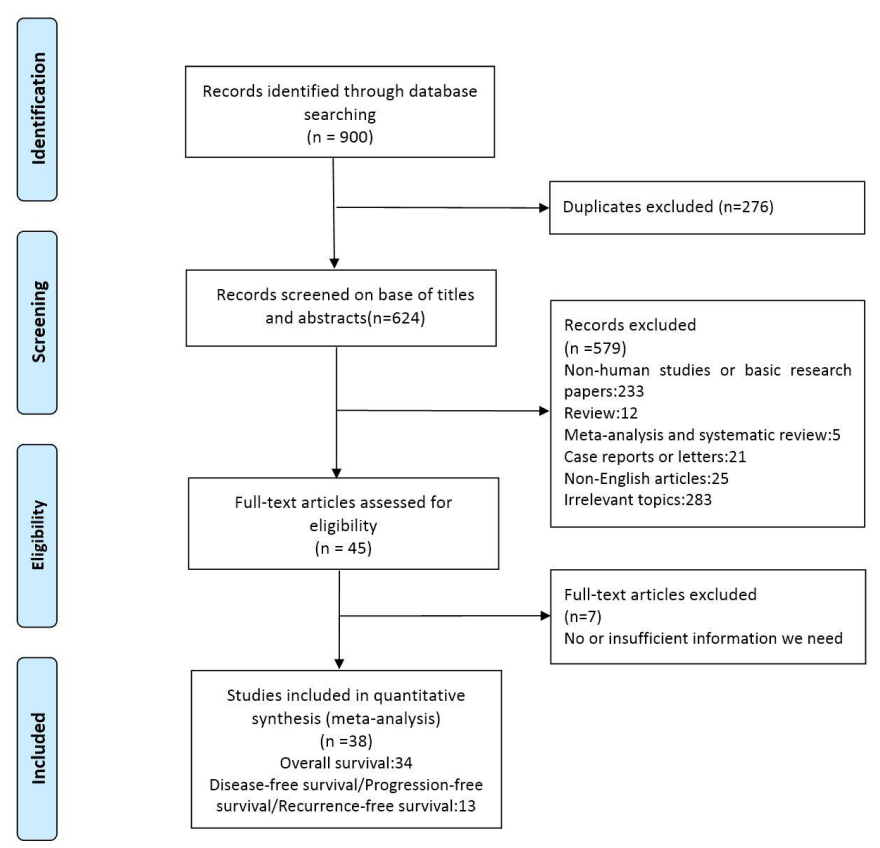

Figure 1 The flow diagram of publications selection. 


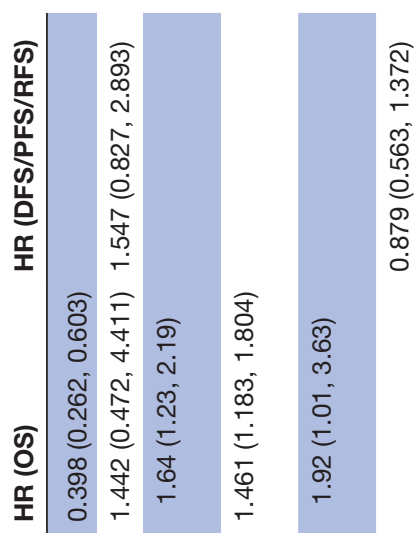

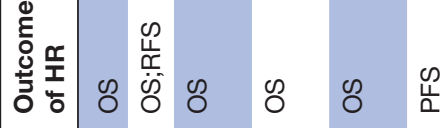

일

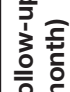

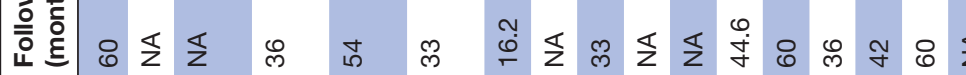

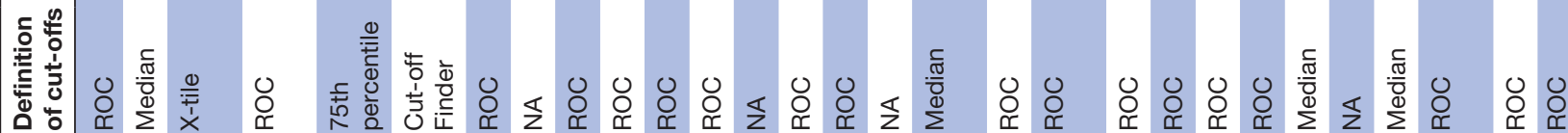

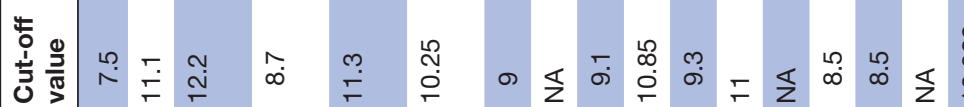

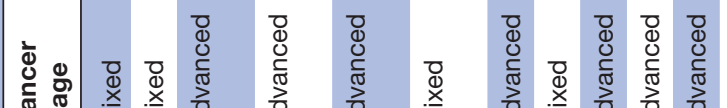

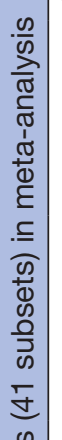

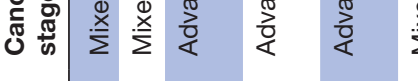

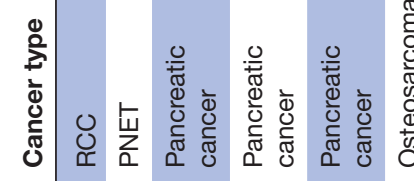

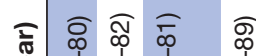

离

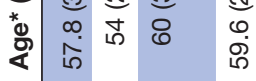

$\frac{0}{\circ}$

产

U

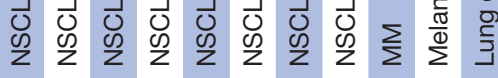

बฐ

O 岱

๙

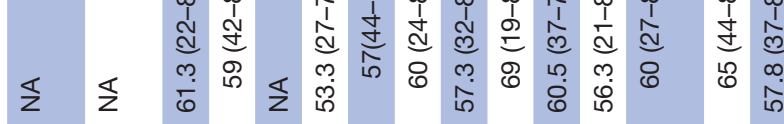

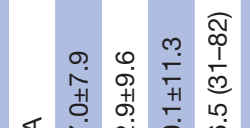

สิ



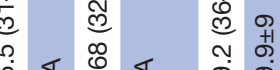

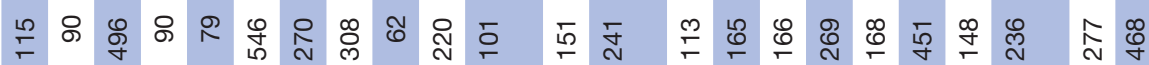

志离

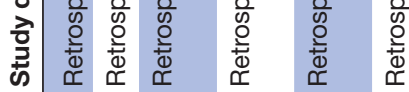

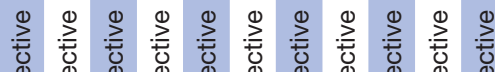

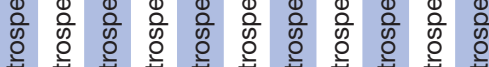

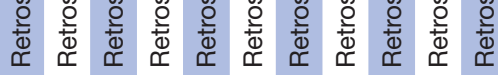

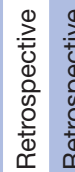

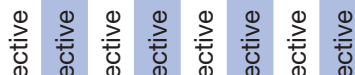

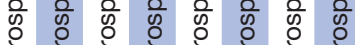

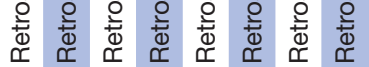

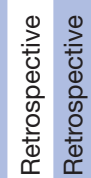

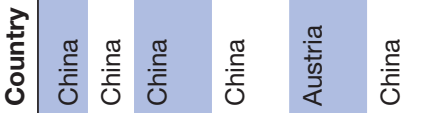

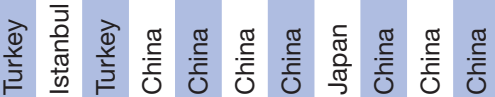

胥

ゆิ

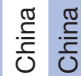

ষ্ঠ

\section{$\stackrel{\frac{\mathfrak{T}}{\mathrm{N}}}{\Sigma}$}

$\frac{-}{\frac{0}{0}}$

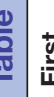

s

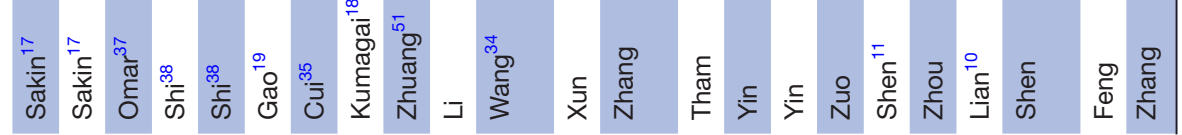




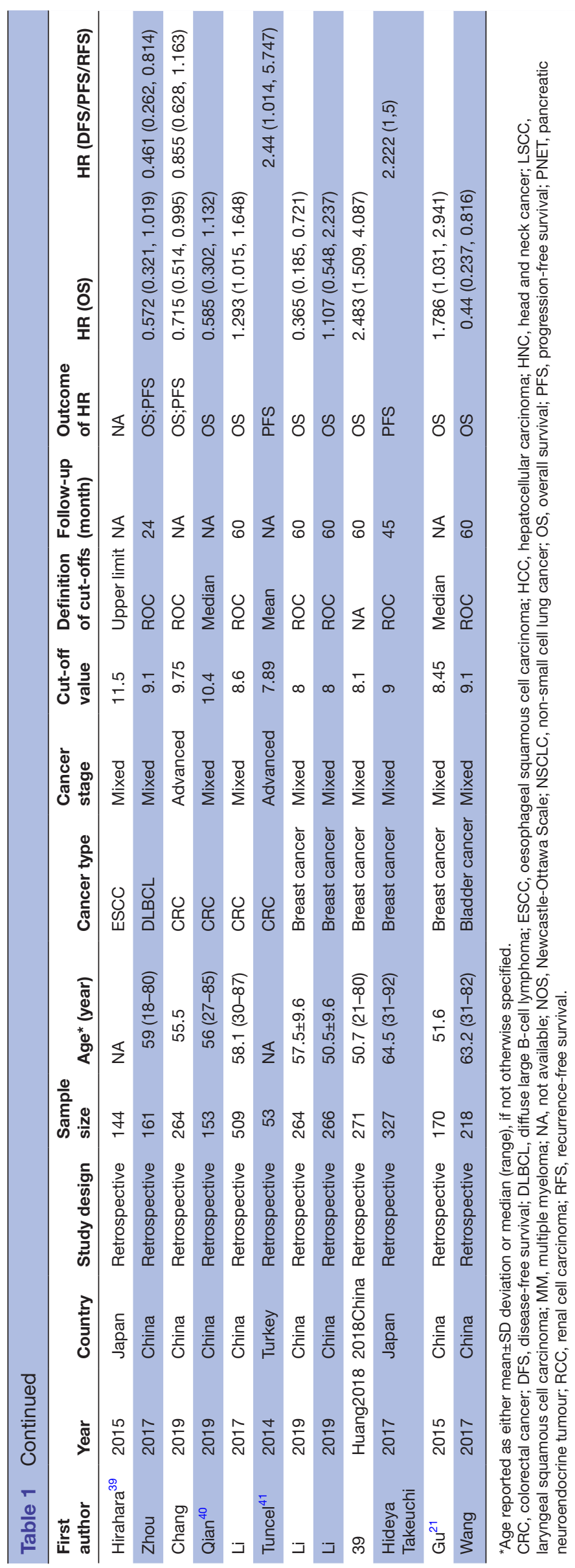




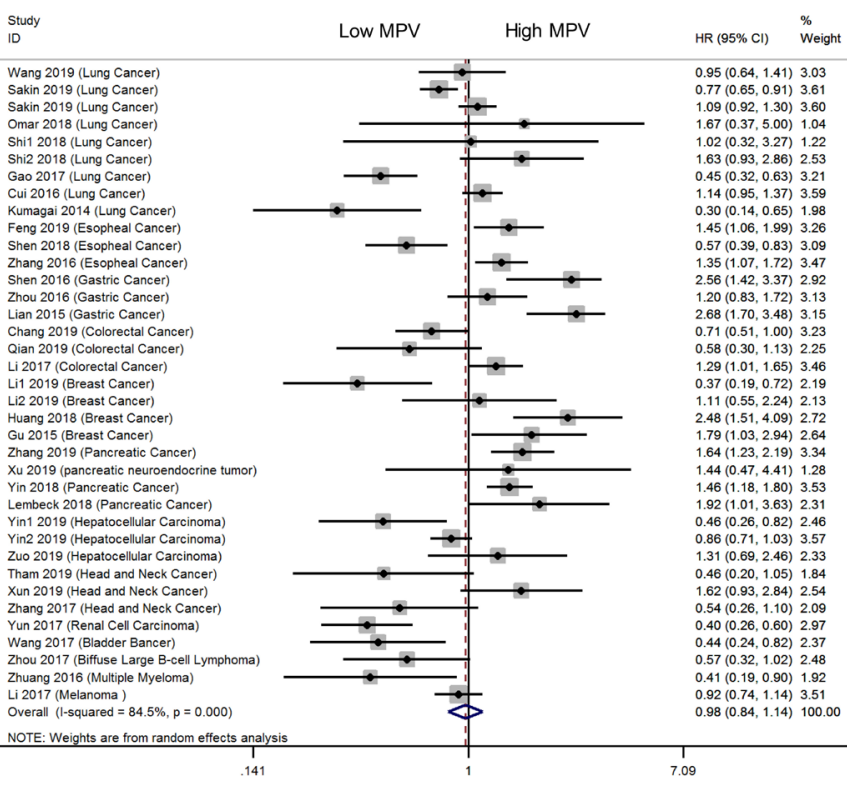

Figure 2 The forest plot between MPV level and OS in patients with cancer. Results are presented as individual and pooled HRs with $95 \%$ Cls. HR $>1$ indicates worse overall survival for the group. MPV, mean platelet volume; OS, overall survival.

irrelevant content were excluded. A full-text review of the remaining 45 articles was conducted. Among them, seven reports were excluded for insufficient or no data to evaluate the association between MPV and prognostic outcomes or clinicopathologic characteristics of cancer patients. Finally, after applying the inclusion and exclusion criteria, 38 eligible studies (41 subsets) including 9894 patients were included in our meta-analysis. ${ }^{7-24} 34-53$ In one of these studies, patients with tumour were divided into two groups according to pathological classification, ${ }^{38}$ and according to whether patients with tumour had type 2 diabetes, the subjects in two other studies were also, respectively, divided into two groups. ${ }^{2044}$ Therefore, a total of six subsets were extracted. The selection process of the included studies according to the Preferred Reporting Items for Systematic Reviews and Meta-Analyses guidelines was shown in figure 1 . The characteristics of the included studies were shown in table 1. OS and DFS/PFS/ RFS were reported in 34 studies (37 subsets) and 13 articles, respectively. Eleven different solid cancer types and two different haematological malignancies were investigated in the eligible studies. Among solid tumours, the most frequently evaluated cancer was upper gastrointestinal cancer (including patients with oesophageal, gastric, and pancreatic cancer) $(\mathrm{n}=11)$, followed by lung cancer $(n=8)$, breast cancer $(n=4)$, colorectal cancer (CRC) $(\mathrm{n}=3)$, head and neck cancer (HNC) $(\mathrm{n}=3)$, hepatic cancer (HCC) $(n=2)$, urothelial carcinoma $(n=2)$, melanoma $(\mathrm{n}=1)$ and osteosarcoma $(\mathrm{n}=1)$. Multiple myeloma $(\mathrm{n}=1)$ and diffuse large B-cell lymphoma $(\mathrm{n}=1)$ were the two haematological malignancies evaluated. A majority of studies $(75.7 \%)$ enrolled patients with mixed-stage cancer, whereas only a few studies $(24.3 \%)$ specifically investigated patients with advanced-stage cancer. Three different types of methods for defining cut-off values were observed in the included studies. The receiver operating characteristic (ROC) curve analysis had the highest frequency of use ( $n=22)$, followed by the empirical value based on previous studies $(n=9)$ and the calculated value obtained via certain computing software $(n=2)$. The cutoff values ranged from 7.4 to 12.2 in the included studies. In addition, 10 studies (33.3\%) included older population, the median or mean age of whom was $\geq 60$ years. Almost all of the studies (94.7\%) were originally from Asia, while the only two remaining studies were from Europe and North America. Among the quality assessment of 38 studies, the quality score of four studies is 6 , and the remaining 32 studies is $\geq 7$.

\section{MPV level and prognosis of cancer}

Thirty-four studies including 37 subsets with 9238 patients were analysed for OS. The pooled HRs of high MPV level was 0.98 (95\% CI 0.84 to 1.14; figure 2), indicating no association between MPV level and OS in cancer patients. Table 2 shows the results for subgroup analysis, which was performed and stratified by six factors including tumour type, tumour stage, age, country of origin, cutoff value and method of defining the cut-off value. In solid tumours, gastric cancer with high MPV had the strongest relationship with poor OS (HR 2.01, 95\% CI 1.18 to 3.41 ; online supplemental figure 1), followed by pancreatic cancer (HR 1.54, 95\% CI 1.31 to 1.82; online supplemental figure 2). Whereas other cancers with higher MPV were not associated with worse OS (NSCLC: HR $0.85,95 \%$ CI 0.64 to 1.15 ; oesophageal cancer: HR $1.05,95 \%$ CI 0.63 to 1.77 ; breast cancer: HR $1.19,95 \%$ CI 0.54 to 2.16 ; CRC: HR $0.86,95 \%$ CI 0.52 to 1.42 ; HCC: HR $0.80,95 \%$ CI 0.51 to 1.27 ; HNC: HR $0.77,95 \%$ CI 0.33 to 1.77$)$. In addition, neither advanced nor mixed-stage tumour patients showed significant relationship between high MPV and poor OS (HR 1.36, 95\% CI 0.96 to 1.94; HR $0.90,95 \%$ CI 0.74 to 1.09 ). There were considerable variations in the methodologies used to define cut-off values. ROC analysis was used widely to define cut-off values and low MPV was significantly related to poor OS in the subgroup of ROC-based cut-offs (HR $0.78,95 \%$ CI 0.64 to 0.95 ). However, the other subgroup did not show a significant correlation between MPV and poor OS (HR $1.51,95 \%$ CI 0.92 to 2.47 ). Sensitivity analysis for OS was performed. The results showed no significant change in the corresponding combined HR, indicating results in this meta-analysis are stable and robust (figure 3).

Thirteen studies with 3014 patients provided HRs and $95 \%$ Cis for DFS. Overall, the pooled data indicated that MPV was not associated with DFS (HR 1.22, 95\% CI 0.86 to 1.73 ; figure 4 ).

\section{Relationship between MPV level and clinicopathological parameters}

To further explore the association between MPV and the clinicopathological parameters in cancer, we extracted 
Table 2 Subgroup analyses of the associations between MPV and OS in cancer

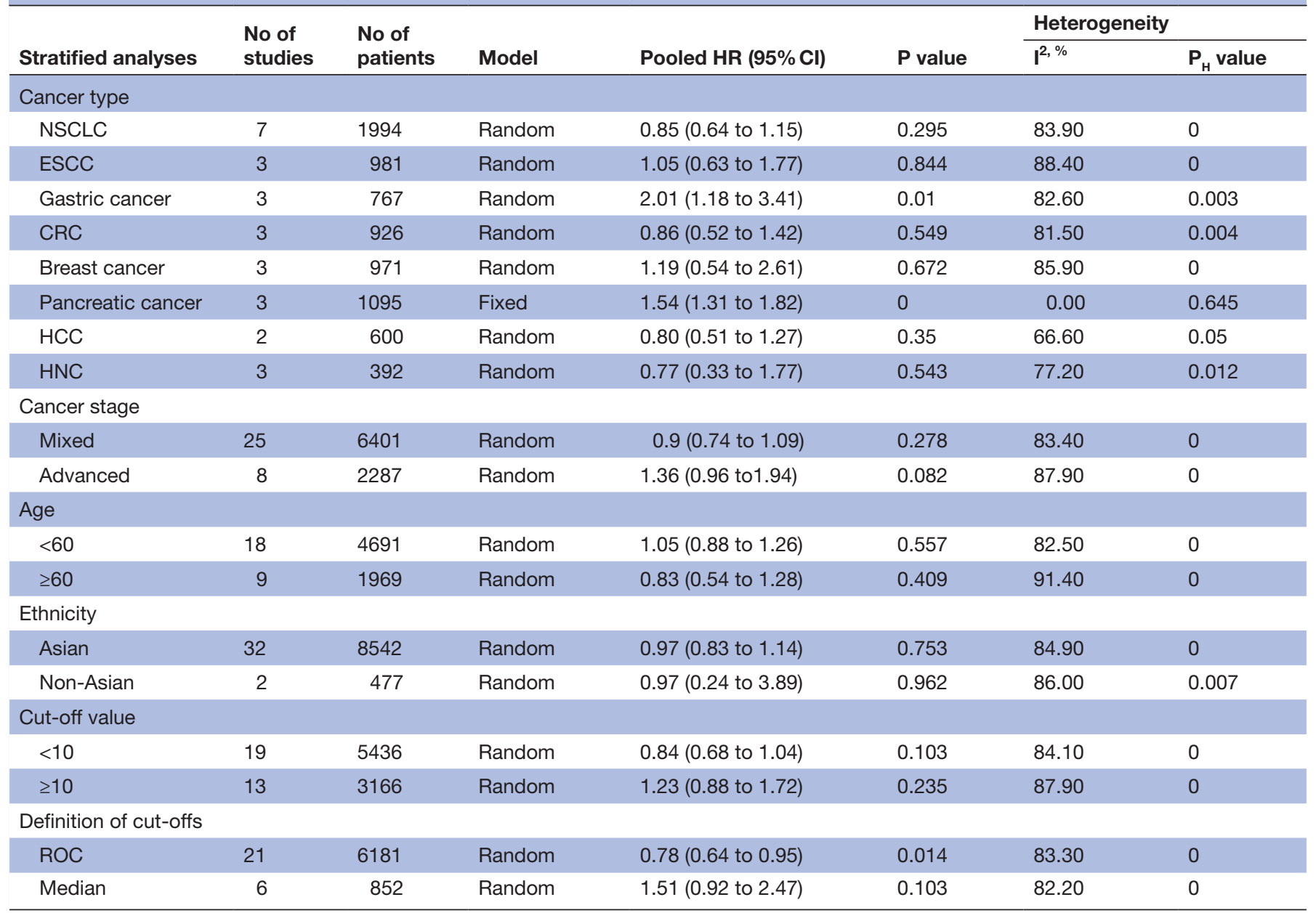

CRC, colorectal cancer; ESCC, oesophageal squamous cell carcinoma; HCC, hepatocellular carcinoma; HNC, head and neck cancer; MPV, mean platelet volume; NSCLC, non-small cell lung cancer; OS, overall survival; ROC, receiver operating characteristic.

parts of included studies based on age, sex, depth of cancer invasion and tumour stage. As shown in table 3, MPV was not shown to be associated with age $(n=13$, OR $0.96,95 \%$ CI 0.90 to 1.02 ), sex ( $n=17$, OR $1.04,95 \%$ CI 1.00 to 1.09$)$, depth of cancer invasion $(n=10$, OR 0.90 , $95 \%$ CI 0.77 to 1.04$)$ and tumour stage $(n=11$, OR 0.91 , $95 \%$ CI 0.78 to 1.07$)$.

\section{Publication bias}

We detected no evidence of obvious asymmetry by the inspection of the Begg's funnel plot (figure 5), and was further confirmed by Egger's tests $(p=0.468)$, showing no noteworthy publication bias in this meta-analysis. Moreover, no publication bias was observed in gastric cancer subgroup $(\mathrm{p}=0.783)$ (see online supplemental figure 3 ) and pancreatic cancer subgroup $(p=0.255)$ (see online supplemental figure 4).

\section{DISCUSSION}

The MPV is a useful parameter for predicting activation of platelets by estimating the average size of platelets. ${ }^{54}$ It is an attractive index to study in clinical scenarios.
The argument of MPV being a valuable biomarker predicting cancer prognosis was triggered due to controversial studies in variety of related cancer studies. A few researches indicated that MPV as an effective indicator can provide important prognostic information for certain cancers, ${ }^{71518}$ but others failed to show its prognostic value on patients with cancers. ${ }^{45} 473$ This inspires us to perform this first meta-analysis to comprehensively evaluate the prognostic significance of MPV for OS and DFS/PFS/RFS in cancers. Pooled results demonstrated that high MPV was not associated with poor survival outcome. It was also not correlated with age, sex, tumour size, depth of cancer invasion and tumour stage. Although the final results of this meta-analysis were negative, they are still very helpful because they can clarify and show the real possible relationship between MPV and cancer prognosis when faced with contradictory study results, thereby further providing reference for clinical work and even guiding it to a certain extent. In addition, the results may provide new ideas and evidence for clinical applications aimed at assessing the prognosis of cancer. And it may inspire to further clinical research of prognostic prediction in patients with cancer. 


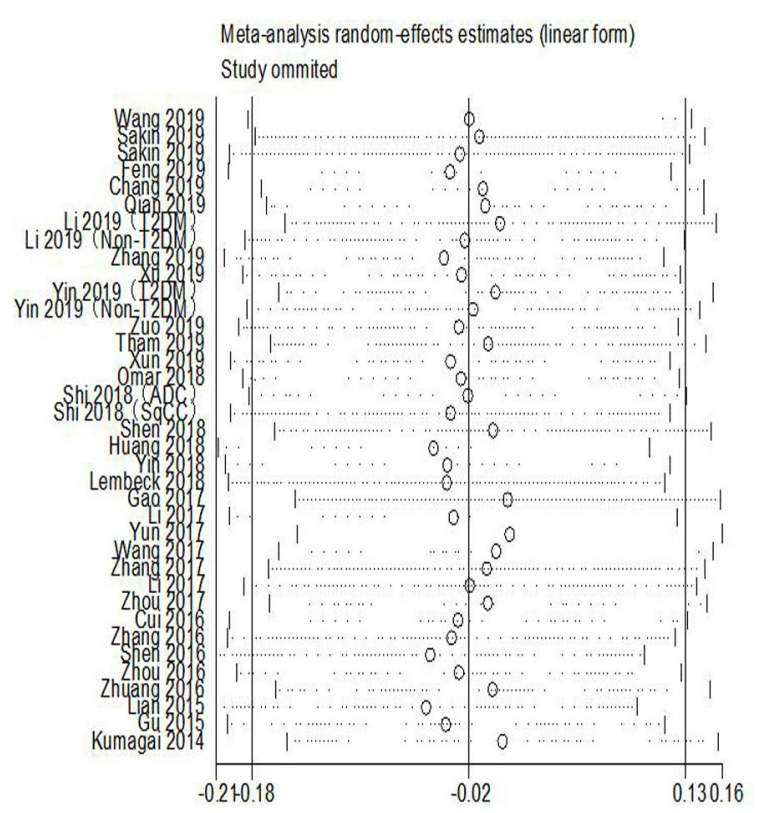

Figure 3 Sensitivity analysis of MPV for OS in patients with cancer. No significant change in the corresponding combined HR was observed, which indicated that our meta-analysis results were stable and robust. MPV, mean platelet volume; OS, overall survival.

A more accurate biological prediction method may, therefore, be developed in the near future.

Subgroup analysis was conducted by age, country of origin, cut-off value, method of defining the cut-off value, tumour stage and tumour type. High MPV was not related to poor OS in older and younger patients with cancers. Similarly, there was no correlation between high MPV and unfavourable OS in subgroups with cutoff values $\geq 10.5$ and $<10.5$. Neither Asian nor non-Asian patients with high MPV exhibited poor OS. Although it was demonstrated that MPV in patients in an early stage of cancer was similar to those found in healthy subjects and increased with the cancer progression, ${ }^{55}$ we observed no significant correlation between high MPV and poor OS in patients with advanced cancers, nor in patients from the mixed-stage subgroup in our analysis. Whereas in the subgroup based on ROC curves method, low MPV was significantly associated with unfavourable OS. But we believe this result requires to verify prognostic significance of an ROC-based cut-off value in validation cohort, since the ROC-based cut-off value is actually a high risk of bias leading to overestimation of sensitivity and specificity in predicting cancer prognosis. Moreover, although high MPV level was obviously related to unfavourable OS for gastric cancer and pancreatic cancer, we still could not rashly conclude that high MPV can predict the poor prognosis of these two types of cancers. Because none of the three pancreatic cancer studies we included had a validation cohort and uniform MPV cut-off values, and these values varied widely. The same goes for three studies on gastric cancer. So more high-quality studies need to be implemented to explore unified cut-off values or priori defined cut-off values (eg, median) for specific cancers. In summary, although the data on gastric and pancreatic cancer were in question, the current results were valuable and could provide a good reference and inspiration for higher quality studies on these specific cancers in the future.

Although the final results of this study showed that pretreatment MPV did not play a significantly effective role in predicting prognosis in cancer, there might be a close association between alteration of MPV level and poor prognosis in certain tumours. We believe there may be some biological reasons behind this. Literatures indicated that MPV level could be influenced by a number

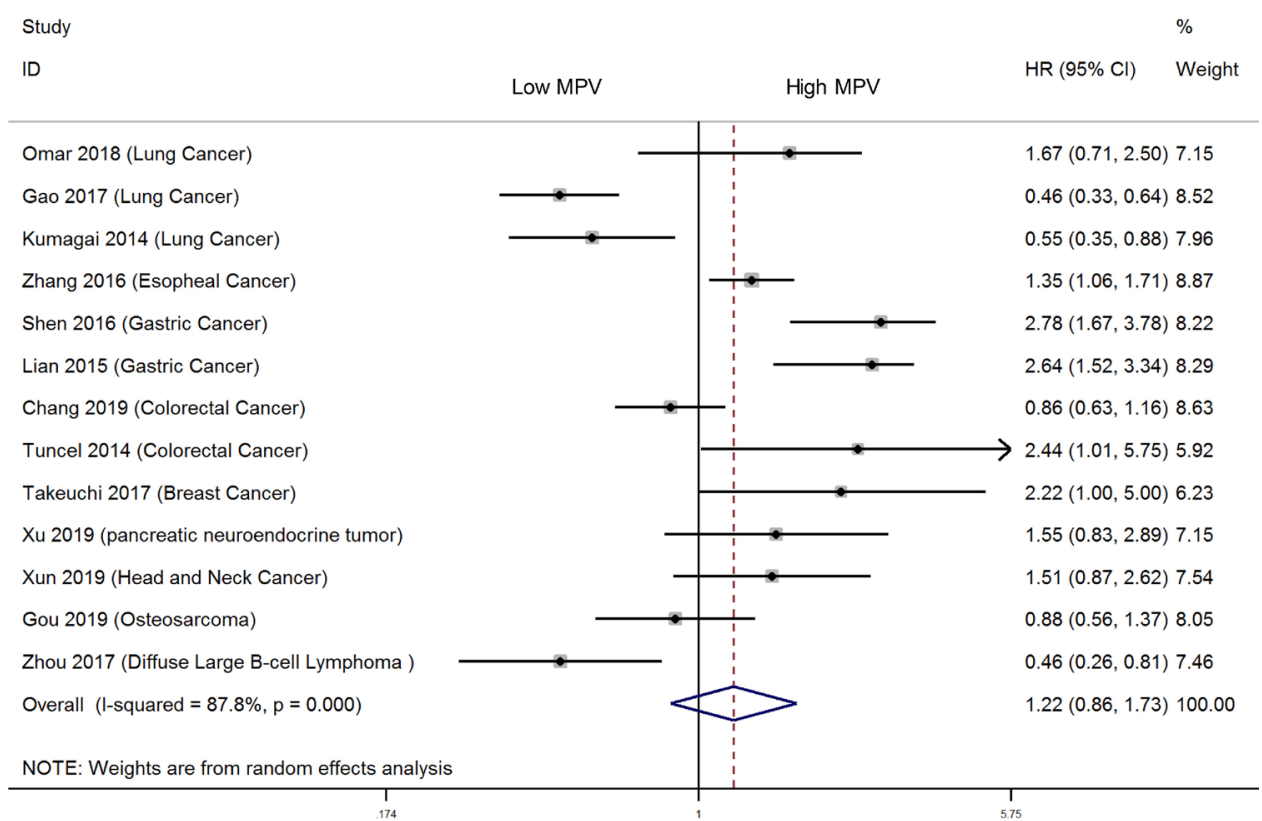

Figure 4 The forest plot between MPV level and DFS in patients with cancer. Results are presented as individual and pooled HRs with $95 \%$ Cls. HR>1 indicates worse overall survival for the group. DFS, disease-free survival; MPV, mean platelet volume. 
Table 3 Association between MPV level and clinicopathological parameters

\begin{tabular}{|c|c|c|c|c|c|c|c|}
\hline \multirow[b]{2}{*}{ Clinical features } & \multirow{2}{*}{$\begin{array}{l}\text { No of } \\
\text { studies }\end{array}$} & \multirow{2}{*}{$\begin{array}{l}\text { No of } \\
\text { patients }\end{array}$} & \multirow[b]{2}{*}{ Model } & \multirow[b]{2}{*}{ OR $(95 \% \mathrm{Cl})$} & \multirow[b]{2}{*}{ P value } & \multicolumn{2}{|c|}{ Heterogeneity } \\
\hline & & & & & & $\mathrm{I}^{2, \%}$ & $P_{H}$ value \\
\hline Age (older vs younger) & 13 & 2968 & Fixed & 0.96 (0.90 to1.02) & 0.155 & 25.40 & 0.188 \\
\hline Depth of invasion (T1+T2 vs T3+T4) & 10 & 2420 & Random & 0.90 (0.77 to 1.04$)$ & 0.149 & 78.10 & 0 \\
\hline Tumour stage (I/II vs III/IV) & 11 & 2425 & Random & 0.91 (0.78 to 1.07$)$ & 0.257 & 78.90 & 0 \\
\hline
\end{tabular}

MPV, mean platelet volume; $P_{H}, p$ values of $Q$ test for heterogeneity test.

of lifestyles and various diseases like smoking, ${ }^{56}{ }^{57}$ hypertension, ${ }^{58}{ }^{59}$ diabetes, ${ }^{60}{ }^{61}$ dyslipidaemia and obesity, ${ }^{62} 63$ cardiocerebrovascular disease ${ }^{6465}$ and inflammatory disorders. ${ }^{66}{ }^{67}$ In essence, inflammation and thrombosis may play a key role in the increase and decrease of MPV level that is closely related to cancer prognosis. It is well known that malignant tumours are accompanied by systemic inflammatory response. ${ }^{6869}$ Numerous inflammatory cytokines (eg, interleukin-1, IL-1, IL-6 and tumour necrosis factor- $\alpha$, TNF- $\alpha$ ) can promote the maturation and proliferation of macrophages ${ }^{70} 71$ and further lead to platelet activation and enhanced release of larger platelets, therefore elevating MPV level. ${ }^{5572}$ Activated platelets can secret a cocktail of predominantly proangiogenic cytokines within a potentially prothrombotic tumour microcirculation and coat circulating tumour cells to protect tumour cells from shear stress and the host's immune response ${ }^{5}$ which promote tumour growth, angiogenesis and metastasis. Therefore, the close association between high MPV

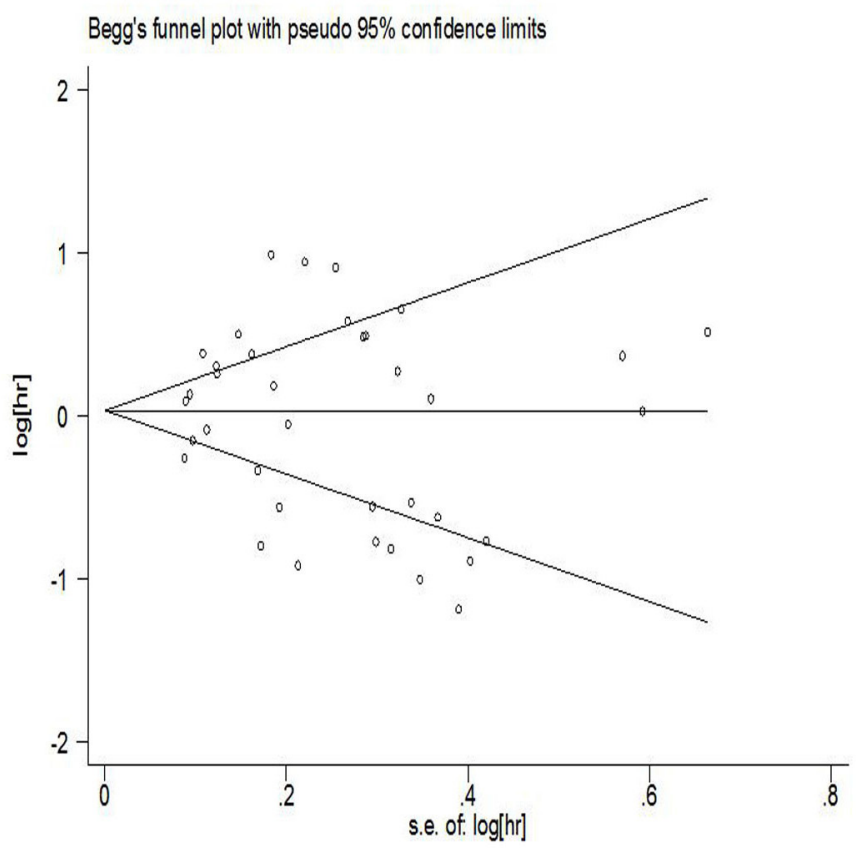

Figure 5 Begg's funnel plot of publication bias test for OS in patients with cancer. No significant publication bias for studies evaluating the association between MPV level and os was observed. MPV, mean platelet volume; OS, overall survival. level and poor prognosis of cancers may be reasonable hypotheses. On the other hand, inflammation aggravation $^{5572}$ and thrombosis ${ }^{5472}$ can lead to a decrease in MPV. When inflammation aggravating, increased release rate of small size platelets due to excessive proinflammatory cytokines' interference with megakaryopoiesis and selective consumption of large amount of highly reactive large-sized platelets result in a decline in MPV. ${ }^{73}$ This suggests that the level of MPV depends heavily on the intensity of the systemic inflammation with the evidence in a recent study that low levels of MPV were associated with severe inflammatory diseases and were reversed during anti-inflammatory treatment. ${ }^{72}$ Moreover, tumour cells release TNF- $\alpha$, IL-1 $\beta$, vascular endothelial growth factor and basic fibroblast growth factor ${ }^{75}$ promoting the formation of vascular endothelial thrombi, in which process the consumption of larger-sized platelets is increased, leading to a decreased MPV in the circulating platelets. ${ }^{76}$ Although decreased MPV might indicate thrombosis that is closely associated with poor survival in patients with cancers, ${ }^{77-79}$ it is still not enough to support the notion for low MPV being an indicator of predicting the poor prognosis of cancer. Instead, it indicates the complicated role of MPV in the cancer development, which is justified to further study.

We admit that there are several limitations in our study. First, the inclusion criteria for this meta-analysis were limited to the studies published in English. And some studies without sufficient data were excluded. Thus publication or data availability bias may exist. Second, almost all of the included studies were retrospective, and the patients included were all but composed of Asian cohort, which may have led to greater susceptibility to bias. However, there was no significant publication bias occurred based on the result in the asymmetry of the funnel plot, thus maintaining the substantial consistency among the results. Third, there was considerable heterogeneity when pooling HRs for OS results. Subgroup analysis showed the cut-off values in the included studies were various, which could lead to heterogeneity between studies. Finally, the majority of the included studies have no validation cohort. Therefore, higher-quality studies are expected to more accurately assess the relationship between MPV and tumour prognosis to obtain more reliable results. This is one of the reasons why we conducted this meta-analysis. 


\section{CONCLUSIONS}

In conclusion, the findings of this meta-analysis suggested that MPV level prior to initial treatment is of no prognostic significance in patients with cancer and no relation with age, sex, tumour size, depth of invasion and tumour stage, providing new ideas and evidence for the clinical application of MPV. Although the results obtained by subgroup analysis were positive, further research is needed. Therefore, cumulative high-quality studies for specific tumours are needed for the exploration and evaluation of reliable and uniform MPV cut-off values in clinical practice and further robust clinical studies are warranted focusing on MPV as prognostic factor of patients with cancer.

\section{Author affiliations \\ ${ }^{1}$ Department of General Surgery, Nantong Tumor Hospital, Nantong, China ${ }^{2}$ Department of General Surgery, Tumor Hospital Affiliated to Nantong University, Nantong, China \\ ${ }^{3}$ Cancer Research Center Nantong, Nantong Tumor Hospital, Nantong, China ${ }^{4}$ Cancer Research Center Nantong, Nantong Tumor Hospital, Nantong Jiangsu, Nantong, China \\ ${ }^{5}$ Department of Oncology, Nantong Tumor Hospital, Nantong, China \\ ${ }^{6}$ Department of Oncology, Tumor Hospital Affiliated to Nantong University, Nantong, China \\ ${ }^{7}$ Department of Pathology, Nantong Tumor Hospital, Nantong, China \\ ${ }^{8}$ Department of Gastrointestinal Surgery, Nantong University Affiliated Hospital, Nantong, China}

Contributors $X C$ and $\mathrm{JL}$ were involved in drafting the manuscript. $\mathrm{XZ}$ and $\mathrm{YL}$ made contributions to the concepts, acquisition and analysis of the data. JW and $Y L$ was involved in acquisition of data and preparing the figures. $\mathrm{XJ}$ and $\mathrm{XC}$ designed and revised the manuscript. All authors have read and approved the final manuscript.

Funding The work was supported by Youth Research Fund Project of the Health and Family Planning Commission of Nantong (QA2019028), Guiding Project of Nantong Municipal Science and Technology Plan (JCZ19110).

Competing interests None declared.

Patient consent for publication Not required.

Provenance and peer review Not commissioned; externally peer reviewed.

Data availability statement Data are available in a public, open access repository. All data for this study are publicly available and are ready for the public to download at no cost from the official websites of the PubMed and EMBASE. There is no need to have the formal permission to use data for this study. The sources and data robustness have been described in the section of 'Methods'.

Open access This is an open access article distributed in accordance with the Creative Commons Attribution Non Commercial (CC BY-NC 4.0) license, which permits others to distribute, remix, adapt, build upon this work non-commercially, and license their derivative works on different terms, provided the original work is properly cited, appropriate credit is given, any changes made indicated, and the use is non-commercial. See: http://creativecommons.org/licenses/by-nc/4.0/.

ORCID iD

Xin Chen http://orcid.org/0000-0002-8344-4023

\section{REFERENCES}

1 Torre LA, Bray F, Siegel RL, et al. Global cancer statistics, 2012. CA Cancer J Clin 2015;65:87-108.

2 Siegel RL, Miller KD, Jemal A. Cancer statistics, 2018. CA Cancer J Clin 2018;68:7-30.

3 Park Y, Schoene N, Harris W. Mean platelet volume as an indicator of platelet activation: methodological issues. Platelets 2002;13:301-6.

4 Bambace NM, Holmes CE. The platelet contribution to cancer progression. J Thromb Haemost 2011;9:237-49.

5 Buergy D, Wenz F, Groden C, et al. Tumor-platelet interaction in solid tumors. Int J Cancer 2012;130:2747-60.
6 Goubran HA, Stakiw J, Radosevic M, et al. Platelet-cancer interactions. Semin Thromb Hemost 2014;40:296-305.

7 Zhang F, Chen Z, Wang P, et al. Combination of platelet count and mean platelet volume (COP-MPV) predicts postoperative prognosis in both resectable early and advanced stage esophageal squamous cell cancer patients. Tumour Biol 2016;37:9323-31.

8 Shen W, Cui M-M, Wang X, et al. Reduced mean platelet volume is associated with poor prognosis in esophageal cancer. Cancer Biomark 2018;22:559-63.

9 Feng J-F, Sheng C, Zhao Q, et al. Prognostic value of mean platelet volume/platelet count ratio in patients with resectable esophageal squamous cell carcinoma: a retrospective study. PeerJ 2019;7:e7246.

10 Lian L, Xia Y-Y, Zhou C, et al. Mean platelet volume predicts chemotherapy response and prognosis in patients with unresectable gastric cancer. Oncol Lett 2015;10:3419-24.

11 Shen X-M, Xia Y-Y, Lian L, et al. Mean platelet volume provides beneficial diagnostic and prognostic information for patients with resectable gastric cancer. Oncol Lett 2016;12:2501-6.

12 Yin J-B, Wang X, Zhang X, et al. Mean platelet volume predicts survival in pancreatic cancer patients with synchronous liver metastases. Sci Rep 2018;8:6014.

13 Lembeck AL, Posch F, Klocker EV, et al. Large platelet size is associated with poor outcome in patients with metastatic pancreatic cancer. Clin Chem Lab Med 2019:57:740-4.

14 Zhang K, Gao H-F, Mo M, et al. A novel scoring system based on hemostatic parameters predicts the prognosis of patients with advanced pancreatic cancer. Pancreatology 2019;19:346-51.

15 Chang J, Lin G, Ye M, et al. Decreased mean platelet volume predicts poor prognosis in metastatic colorectal cancer patients treated with first-line chemotherapy: results from $\mathrm{mCRC}$ biomarker study. BMC Cancer 2019;19:15.

16 Li N, Yu Z, Zhang X, et al. Elevated mean platelet volume predicts poor prognosis in colorectal cancer. Sci Rep 2017;7:10261.

17 Sakin A, Secmeler S, Arici S, et al. Prognostic significance of mean platelet volume on local advanced non-small cell lung cancer managed with chemoradiotherapy. Sci Rep 2019;9:3959.

18 Kumagai S, Tokuno J, Ueda Y, et al. Prognostic significance of preoperative mean platelet volume in resected non-small-cell lung cancer. Mol Clin Oncol 2015;3:197-201.

19 Gao L, Zhang H, Zhang B, et al. Prognostic value of combination of preoperative platelet count and mean platelet volume in patients with resectable non-small cell lung cancer. Oncotarget 2017;8:15632-41.

20 Li N, Lv X-H, Wang X, et al. Preoperative mean platelet volume predicts survival in breast cancer patients with type 2 diabetes. Breast Cancer 2019;26:712-8.

21 Gu M, Zhai Z, Huang L, et al. Pre-treatment mean platelet volume associates with worse clinicopathologic features and prognosis of patients with invasive breast cancer. Breast Cancer 2016;23:752-60.

22 Huang Y, Cui M-M, Huang Y-X, et al. Preoperative platelet distribution width predicts breast cancer survival. Cancer Biomark 2018;23:205-11.

23 Yun Z-Y, Zhang X, Liu Y-S, et al. Lower mean platelet volume predicts poor prognosis in renal cell carcinoma. Sci Rep 2017;7:6700.

24 Wang X, Cui M-M, Xu Y, et al. Decreased mean platelet volume predicts poor prognosis in invasive bladder cancer. Oncotarget 2017;8:68115-22.

25 Stang A. Critical evaluation of the Newcastle-Ottawa scale for the assessment of the quality of nonrandomized studies in metaanalyses. Eur J Epidemiol 2010;25:603-5.

26 Miao C, Liang C, Zhu J, et al. Prognostic role of matrix metalloproteinases in bladder carcinoma: a systematic review and meta-analysis. Oncotarget 2017;8:32309-21.

27 Zhao Y, Si G, Zhu F, et al. Prognostic role of platelet to lymphocyte ratio in hepatocellular carcinoma: a systematic review and metaanalysis. Oncotarget 2017;8:22854-62.

28 Wang P-F, Song S-Y, Guo H, et al. Prognostic role of pretreatment red blood cell distribution width in patients with cancer: a metaanalysis of 49 studies. $J$ Cancer 2019;10:4305-17.

29 Tierney JF, Stewart LA, Ghersi D, et al. Practical methods for incorporating summary time-to-event data into meta-analysis. Trials 2007;8:16.

30 Higgins JPTet al. Measuring inconsistency in meta-analyses. BMJ 2003;327:557-60.

31 Mantel N, Haenszel W. Statistical aspects of the analysis of data from retrospective studies of disease. J Natl Cancer Inst 1959;22:719-48.

32 Begg CB, Mazumdar M. Operating characteristics of a RANK correlation test for publication bias. Biometrics 1994;50:1088-101.

33 Egger M, Smith GD, Schneider M, et al. Bias in meta-analysis detected by a simple, graphical test. BMJ 1997;315:629-34. 
34 Wang J-J, Wang Y-L, Ge X-X, et al. Prognostic values of plateletassociated indicators in resectable lung cancers. Technol Cancer Res Treat 2019;18:153303381983726.

35 Cui M-M, Li N, Liu X, et al. Platelet distribution width correlates with prognosis of non-small cell lung cancer. Sci Rep 2017;7:3456.

36 Sakin A, Yasar N, Arici S, et al. Effect of pretreatment platelet parameters on survival in limited disease small cell lung cancer. Asian Pac J Cancer Prev 2019;20:1879-85.

37 Omar M, Tanriverdi O, Cokmert S, et al. Role of increased mean platelet volume (MPV) and decreased MPV/platelet count ratio as poor prognostic factors in lung cancer. Clin Respir J 2018;12:922-9.

38 Shi L, Li Y, Yu T, et al. Predictable resistance and overall survival of gemcitabine/cisplatin by platelet activation index in non-small cell lung cancer. Med Sci Monit 2018;24:8655-68.

39 Hirahara N, Matsubara T, Kawahara D, et al. Prognostic value of hematological parameters in patients undergoing esophagectomy for esophageal squamous cell carcinoma. Int $J$ Clin Oncol 2016;21:909-19.

40 Qian W, Ge X-X, Wu J, et al. Prognostic evaluation of resectable colorectal cancer using platelet-associated indicators. Oncol Lett 2019;18:571-80.

41 Tuncel T, Ozgun A, Emirzeoglu L, et al. Mean platelet volume as a prognostic marker in metastatic colorectal cancer patients treated with bevacizumab-combined chemotherapy. Asian Pac J Cancer Prev 2014;15:6421-3.

42 Takeuchi H, Abe M, Takumi Y, et al. The prognostic impact of the platelet distribution width-to-platelet count ratio in patients with breast cancer. PLoS One 2017;12:e0189166.

43 Xu S-S, Xu H-X, Wang W-Q, et al. Tumor-infiltrating platelets predict postoperative recurrence and survival in resectable pancreatic neuroendocrine tumor. World J Gastroenterol 2019;25:6248-57.

44 Yin J-B, Niu Y, Qian L-Y, et al. Mean platelet volume predicts survival in patients with hepatocellular carcinoma and type 2 diabetes. Diabetes Res Clin Pract 2019;151:120-7.

45 Zuo X, Kong W, Feng L, et al. Elevated platelet distribution width predicts poor prognosis in hepatocellular carcinoma. Cancer Biomark 2019;24:307-13.

46 Tham T, Leung E, Olson C, et al. Evaluation of the prognostic utility of the combination of platelet count with mean platelet volume as a prognostic indicator in head and neck cancer. Mol Clin Oncol 2019;10:457-62.

47 Zhang H, Liu L, Fu S, et al. Higher platelet distribution width predicts poor prognosis in laryngeal cancer. Oncotarget 2017;8:48138-44.

48 Xun $\mathrm{Y}$, Wang $\mathrm{M}$, Sun $\mathrm{H}$, et al. Prognostic analysis of preoperative inflammatory biomarkers in patients with laryngeal squamous cell carcinoma. Ear Nose Throat J 2020;99:371-8.

49 Li N, Diao Z, Huang X, et al. Increased platelet distribution width predicts poor prognosis in melanoma patients. Sci Rep 2017;7:2970.

50 Gou B, Cao H, Cheng X, et al. Prognostic value of mean platelet volume to plateletcrit ratio in patients with osteosarcoma. Cancer Manag Res 2019;11:1615-21.

51 Zhuang Q, Xiang $\mathrm{L}$, Xu $\mathrm{H}$, et al. The independent association of mean platelet volume with overall survival in multiple myeloma. Oncotarget 2016;7:62640-6.

52 Zhou S, Ma Y, Shi Y, et al. Mean platelet volume predicts prognosis in patients with diffuse large B-cell lymphoma. Hematol Oncol 2018;36:104-9.

53 Zhou X, Xu L, Huang Z, et al. The hematologic markers as prognostic factors in patients with resectable gastric cancer. Cancer Biomark 2016;17:359-67.

54 Mutlu $\mathrm{H}$, Artis TA, Erden A, et al. Alteration in mean platelet volume and platicrit values in patients with cancer that developed thrombosis. Clin Appl Thromb Hemost 2013:19:331-3.

55 Korniluk A, Koper-Lenkiewicz OM, Kamińska J, et al. Mean platelet volume (MPV): new perspectives for an old marker in the course and prognosis of inflammatory conditions. Mediators Inflamm 2019;2019:9213074
56 Alyan O, Kaçmaz F, Ozdemir O, et al. [High levels of high-sensitivity C-reactive protein and impaired autonomic activity in smokers]. Turk Kardiyol Dern Ars 2008;36:368-75.

57 Butkiewicz AM, Kemona-Chetnik I, Dymicka-Piekarska V, et al. Does smoking affect thrombocytopoiesis and platelet activation in women and men? Adv Med Sci 2006;51:123-6.

58 Varol E, Akcay S, Icli A, et al. Mean platelet volume in patients with prehypertension and hypertension. Clin Hemorheol Microcirc 2010;45:67-72.

59 Boos CJ, Beevers GD, Lip GYH. Assessment of platelet activation indices using the ADVIATM 120 amongst 'high-risk' patients with hypertension. Ann Med 2007;39:72-8.

60 Coban E, Bostan F, Ozdogan M. The mean platelet volume in subjects with impaired fasting glucose. Platelets 2006;17:67-9.

61 Zuberi BF, Akhtar N, Afsar S. Comparison of mean platelet volume in patients with diabetes mellitus, impaired fasting glucose and nondiabetic subjects. Singapore Med J 2008;49:114-6.

62 Pathansali R, Smith N, Bath P. Altered megakaryocyte-platelet haemostatic axis in hypercholesterolaemia. Platelets 2001;12:292-7.

63 Coban E, Ozdogan M, Yazicioglu G, et al. The mean platelet volume in patients with obesity. Int J Clin Pract 2005;59:981-2.

64 Chu SG, Becker RC, Berger PB, et al. Mean platelet volume as a predictor of cardiovascular risk: a systematic review and metaanalysis. J Thromb Haemost 2010;8:148-56.

65 Ntaios G, Gurer O, Faouzi M, et al. Hypertension is an independent predictor of mean platelet volume in patients with acute ischaemic stroke. Intern Med J 2011;41:691-5.

66 Kisacik B, Tufan A, Kalyoncu U, et al. Mean platelet volume (MPV) as an inflammatory marker in ankylosing spondylitis and rheumatoid arthritis. Joint Bone Spine 2008;75:291-4.

67 Gasparyan AY, Sandoo A, Stavropoulos-Kalinoglou A, et al. Mean platelet volume in patients with rheumatoid arthritis: the effect of anti-TNF- $\alpha$ therapy. Rheumatol Int 2010;30:1125-9.

68 Hanahan D, Weinberg RA. Hallmarks of cancer: the next generation. Cell 2011;144:646-74.

69 Balkwill F, Coussens LM. Cancer: an inflammatory link. Nature 2004:431:405-6.

$70 \mathrm{Kim}$ D-K, Oh SY, Kwon H-C, et al. Clinical significances of preoperative serum interleukin-6 and C-reactive protein level in operable gastric cancer. BMC Cancer 2009;9:155.

71 Pop V-V, Seicean A, Lupan I, et al. IL-6 roles - Molecular pathway and clinical implication in pancreatic cancer - A systemic review. Immunol Lett 2017;181:45-50.

72 Gasparyan AY, Ayvazyan L, Mikhailidis DP, et al. Mean platelet volume: a link between thrombosis and inflammation? Curr Pharm Des 2011;17:47-58.

73 Cornillie F, Hanauer SB, Diamond RH, et al. Postinduction serum infliximab trough level and decrease of C-reactive protein level are associated with durable sustained response to infliximab: a retrospective analysis of the accent I trial. Gut 2014:63:1721-7.

74 Thompson CB, Jakubowski JA. The pathophysiology and clinical relevance of platelet heterogeneity. Blood 1988;72:1-8.

75 Falanga A, Panova-Noeva M, Russo L. Procoagulant mechanisms in tumour cells. Best Pract Res Clin Haematol 2009;22:49-60.

76 Mutlu H, Berk V, Karaca H, et al. Treatment regimen with bevacizumab decreases mean platelet volume in patients with metastatic colon cancer. Clin Appl Thromb Hemost 2012;18:546-8.

77 Kristinsson SY, Fears TR, Gridley G, et al. Deep vein thrombosis after monoclonal gammopathy of undetermined significance and multiple myeloma. Blood 2008;112:3582-6.

78 Kristinsson SY, Pfeiffer RM, Björkholm M, et al. Arterial and venous thrombosis in monoclonal gammopathy of undetermined significance and multiple myeloma: a population-based study. Blood 2010;115:4991-8.

79 Kristinsson SY, Pfeiffer RM, Björkholm M, et al. Thrombosis is associated with inferior survival in multiple myeloma. Haematologica 2012:97:1603-7. 